\title{
Um Caderno Digital nos laptops educacionais: proposta conceitual e ferramenta
}

\author{
Diego Soares Cardoso \\ Instituto de Computação - Universidade Estadual de \\ Campinas - Caixa Postal 6176 • Av. Albert Einstein, 1251 \\ - Cidade Universitária • CEP 13083-970 • Campinas/SP \\ diego.cardoso@students.ic.unicamp.br
}

\author{
Maria Cecília Calani Baranauskas \\ Instituto de Computação \& NIED - Universidade Estadual \\ de Campinas - Caixa Postal 6176• Av. Albert Einstein, \\ 1251 - Cidade Universitária • CEP 13083-970• \\ Campinas/SP \\ cecilia@ic.unicamp.br
}

\begin{abstract}
Resumo A eficiência dos tradicionais e predominantes métodos de ensino vem sendo colocada em questão há algumas décadas. Inspirados pelas obras de grandes nomes da Pedagogia e Psicologia, novos ambientes de aprendizado têm sido propostos e emergem de análises de falhas das escolas atuais. A Associação OLPC (One Laptop Per Child), embasada, sobretudo, na teoria Construcionista de aprendizagem, propõe a utilização de laptops individuais de baixo custo em salas de aula como uma forma de dinamizar e revolucionar o processo de ensino-aprendizagem no mundo. Junto a soluções de hardware e software de baixo custo, tal proposta demanda aplicações educacionais em consonância com natureza proposta para tal projeto. Este artigo apresenta as etapas de concepção, projeto e desenvolvimento de uma ferramenta alinhada à proposta da OLPC para uso educacional em laptops de baixo custo: o Caderno Digital. Testes preliminares indicam a viabilidade da proposta e seu potencial como ferramenta de apoio a processos de aprendizagem.
\end{abstract}

Palavras-chave: OLPC, XO, Software Educacional, Construcionismo

\begin{abstract}
Questioning about the efficiency of traditional teaching methods has been brought to surface during the past few decades. Inspired by the works of great names from Pedagogy and Psychology, new learning environments have been proposed and they emerge from analysis of today's schools flaws. The OLPC (One Laptop Per Child) Association, based on the Constructionist learning theory, has individual low-cost laptops in classrooms as its proposal core, whose expectations are for a more dynamic educational process worldwide. Besides solutions regarding low cost hardware and software, such proposal demands educational applications in accordance with the nature of such project. This paper presents the inception, design and development steps of an educational tool aligned to the proposal of the OLPC: the Digital Notebook. Preliminary tests suggest its feasibility and potential utility as a support tool for learning processes.
\end{abstract}

Keywords: OLPC, XO, Educational Software, Constructionism. 


\section{Introdução}

Em 2005, durante o Fórum Econômico Mundial em Davos, Suiça, foi apresentado pela primeira vez o projeto de autoria do MIT Media Lab para reformular e revolucionar o processo de ensino-aprendizagem [1]. Sua idéia básica, inspirada na teoria Construcionista de aprendizagem [2], consistia em levar computadores portáteis para as salas de aula, disponibilizando a professores e alunos os recursos e funcionalidades que um laptop poderia oferecer. A iniciativa foi batizada de One Laptop Per Child (um laptop por criança), ou OLPC.

A Associação OLPC encarregou-se da produção dos laptops, fabricados com baixo custo e vendidos sem qualquer lucro. A fim de garantir seu acesso a cada região do planeta, um valor de custo final foi fixado, criando, então, o conceito do "laptop de cem dólares". Posteriormente, tal máquina passou a ser denominada apenas "XO" (O nome "XO" não constitui sigla ou acrônimo. Não há indicações do fabricante a respeito das razões para a escolha das letras).

O sistema operacional do XO é baseado na distribuição Fedora do Linux e apresenta uma interface gráfica remodelada para o uso por crianças: Sugar [3]. Os softwares inclusos no laptop possuem cunho educacional e código aberto, atendendo aos anseios de um projeto que prima pela colaboração - seja ela promovida pelas redes Mesh [3], que interligam as crianças usuárias, ou pela crescente comunidade de desenvolvedores voluntários na Internet.

Entre estas aplicações pré-instaladas no XO estão presentes navegadores Web, ferramentas de desenho e de composição musical, leitores de RSS e PDF e um editor de textos simplificado [3]. A ação de realizar uma breve anotação explícita sobre qualquer conteúdo seja ele importado ou de autoria própria, como ocorre naturalmente no "caderno escolar", não é permitida em nenhum dos softwares presentes. No ambiente de utilização do XO, tal característica mostra-se desejável, por permitir, principalmente, sintetizar e destacar pontos específicos do conteúdo, principalmente em grandes quantidades de informação.

Desde o lançamento de sua proposta, a OLPC obteve o comprometimento de diversos países, dentre os quais muitos já receberam parte do total de máquinas requisitadas para iniciarem projetos-piloto, com destaque para Peru, México e Uruguai [4].

As primeiras avaliações de tais atividades, baseadas na experiência do Proyeto Ceibal na cidade uruguaia de Villa Cardal, relatam uma notável alteração da dinâmica em sala de aula e destacam, sobretudo, um relevante aumento do interesse dos alunos pela leitura e escrita, além de intenso compartilhamento de experiências entre as crianças [5].

Neste contexto, surge a proposta do Caderno Digital, uma ferramenta com foco sobre o aluno e usuário do laptop educacional. Auxiliar o aprendiz na organização de conteúdos e síntese de conceitos foi o objetivo central do projeto.

O Caderno Digital é produto de uma combinação entre um editor de textos convencional e uma ferramenta de livre anotação. Tal cruzamento de funcionalidades proporciona uma dinâmica diferente às operações de produção, revisão e organização de informações, até então não presente no ambiente do XO.

Este artigo apresenta um panorama da fundamentação teórica do projeto OLPC, cujo papel foi central nas decisões conceituais de elaboração da ferramenta, bem como os detalhes das etapas de avaliação da proposta, desenvolvimento e teste do Caderno Digital.

O restante do artigo está organizado conforme segue: a Seção 2 descreve os pontos principais das teorias que fundamentaram a concepção do projeto; na Seção 3 são apresentados, segundo a bibliografia consultada, o panorama atual e os novos caminhos da educação no Brasil; a Seção 4 exibe a concepção da ferramenta. Questões específicas das decisões técnicas de design e implementação do software são dispostas na Seção 5. A metodologia e os resultados dos testes com usuários são apresentados na Seção 6. A Seção 7 expõe a conclusão.

\section{Bases Teóricas da Ferramenta Proposta}

O contexto de utilização de software em ambiente educacional e sua inserção em uma proposta com bases teóricas explícitas exigem uma metodologia própria para o desenvolvimento de software. É necessário, sobretudo, observar e entender o papel da aplicação a ser construída. Para tal, faz-se necessário articular conhecimentos básicos sobre teorias de aprendizagem. Por se tratar de um projeto de caráter interdisciplinar, visualizá-lo apenas pelo prisma da informática limitaria sua compreensão.

Dessa maneira, as bases teóricas da pesquisa foram construídas sobre três pilares principais, que são discutidos a seguir:

- Teorias relacionadas ao Construcionismo;

- Teoria Construcionista de aprendizagem;

- Paradigmas de Softwares Educacionais. 


\subsection{Teorias relacionadas ao Construcionismo}

Nesta categoria destacamos a Epistemologia Genética e o Construtivismo de Piaget [6], o Sócio-interacionismo de Vygotsky [7] e a obra de Paulo Freire [8]. São destacados a seguir os pontos fundamentais de cada teoria, bem como seus aspectos relevantes ao projeto da ferramenta.

\subsection{1 - A Epistemologia Genética:}

Segundo Bock et al [9], o estudo do desenvolvimento humano é composto pela observação do desenvolvimento mental e do crescimento orgânico. Os autores apontam ainda que, ao contrário do crescimento orgânico, o desenvolvimento mental é um processo contínuo de construção caracterizado pelo aparecimento de estruturas mentais que tendem a se aperfeiçoarem, solidificarem e buscarem um estado de equilíbrio. As pesquisas de Piaget comprovaram que no desenvolvimento humano existem estágios bem definidos que apresentam formas próprias de perceber, compreender e se comportar diante do mundo.

A teoria do desenvolvimento humano atribuída a Jean Piaget, conhecida como Epistemologia Genética, aborda o aspecto intelectual deste processo, isto é, a capacidade de pensamento e raciocínio. Bock et al [9] mostram que, segundo esta teoria, o desenvolvimento humano divide-se em quatro períodos, caracterizados pelo que o indivíduo é capaz de fazer melhor. Furth [10 p.227] conceitua tais estágios como:

"Períodos sucessivos do desenvolvimento da inteligência, cada qual caracterizado por uma estrutura geral relativamente estável que incorpora a uma síntese, superior estruturas anteriores de desenvolvimento".

Segue uma breve descrição de cada período, cujo início e duração dependem de cada indivíduo:

- Período Sensório-motor (entre 0 e 2 anos aproximadamente): a noção de mundo da criança se dá basicamente pela manipulação. Ela conquista o universo que a cerca através da percepção e dos movimentos. Furth [10] atribui a este período as etapas de formação do objeto e de formação do símbolo e a noção de “inteligência prática”. Piaget [11] descreve este estágio como uma "revolução copérnica em miniatura", uma vez que a criança, inicialmente egocêntrica, passa a entender seu corpo como um entre os muitos objetos de seu universo.

- Período Pré-Operatório (entre 2 e 7 anos aproximadamente): todas as modificações intelectuais, afetivas e sociais do período se devem ao aparecimento da linguagem. O desenvolvimento do pensamento se acelera, surgem sentimentos interindividuais, como o respeito aos que ela julga serem superiores e, aliada à maturação neurofisiológica, a criança desenvolve novas habilidades, como a coordenação motora fina, possibilitando a execução dos delicados movimentos da escrita [9].

- Período das Operações Concretas ou Pré-Operatório (entre 7 e 12 anos aproximadamente): a criança é capaz de utilizar raciocínio lógico e lidar com mais de um ponto de vista para uma determinada situação. Este período "é a fase preparatória do estágio da inteligência operatória concreta, caracterizado pela necessidade deformadora de apoio simbólico, donde o egocentrismo" [10 p.230]. A criança é capaz de pensar antes de agir e recuperar o passado para antecipar o futuro e, no campo moral e afetivo, a criança aprende a trabalhar em grupo sem deixar de apresentar autonomia pessoal, organizando seus próprios valores e sentimentos [9].

- Período das Operações Formais (aproximadamente a partir dos 12 anos): Bock et al [9 p.105] caracterizam esse período pela transição do pensamento concreto para o pensamento abstrato, isto é, as operações ocorrem no "plano das idéias, sem necessidade de manipulação ou referências concretas”. Os autores afirmam ainda que, diante do mundo, o adolescente é capaz de abstrair, generalizar e criar teorias e, no aspecto social, o início do período é marcado por uma interiorização aparentemente anti-social: o indivíduo se afasta da família e rejeita conselhos de adultos a fim de realizar uma reflexão sobre a sociedade, sempre analisada como passível de ser reformada e transformada.

\subsection{2 - O Construtivismo:}

Apoiada nas pesquisas de Piaget sobre os estágios de desenvolvimento humano, a teoria construtivista defende um modelo biológico para a construção das idéias. Neste modelo, a capacidade de realizar condutas seletivas, denominada organização, permite ao indivíduo atender suas necessidades e sua demanda à adaptação [9].

O mecanismo de adaptação é o responsável pela inteligência e pelo aprendizado e é constituído por dois processos indissociáveis: assimilação e acomodação. A assimilação é o "processo incorporador de uma ação operativa” [10 p.226] e "refere-se àquilo que é essencial a todo conhecimento, ou seja, uniformidade, atributos comuns e generalização numa dada situação" [10 p.37]. Já a acomodação, "processo exteriorizante de uma ação operativa orientada no sentido de alguma realidade particular" [10 p.225], "refere-se àquilo que é particular, novo e diferente, proporcionando assim a base para a mudança e aprendizagem" [10 p.37].

Novos conhecimentos, ou estruturas mentais, são 
então resultado de uma contínua busca pelo equilíbrio entre assimilação e acomodação, denominada equilibração, e este processo proporciona o desenvolvimento intelectual do indivíduo [9]. Os conhecimentos acumulados são mantidos como um conjunto de modelos operacionais, que são essencialmente algoritmos e estratégias e que, sobretudo em crianças, não seguem necessariamente regras lógicas [12].

Para o Construtivismo, conhecimento não pode ser imposto ou transferido intacto, e, por isso, aprender e ensinar não são sinônimos: ensinar bem não garante o aprendizado [13]. Desse modo, o aluno é o responsável pelo seu próprio processo de aprendizagem.

A aprendizagem construtivista valoriza atividades contextualizadas como uma oportunidade para que os aprendizes descubram e construam seu conhecimento. Cada aluno é tratado como um indivíduo único e os instrutores exercem o papel de facilitadores do aprendizado. $\mathrm{Na}$ ótica do Construtivismo, a aquisição de conhecimento ocorre de forma integrada, isto é, sem divisão em assuntos ou disciplinas, e é um processo ativo e social.

\subsection{3 - O Sócio-interacionismo:}

Lev Vygotsky construiu propostas teóricas sobre a relação entre pensamento e linguagem, a natureza do processo de desenvolvimento da criança e sobre o papel da instrução no desenvolvimento. Dessa forma, sua concepção de desenvolvimento humano está intimamente ligada aos processos de aprendizagem.

Bock et al [9] apontam que o pressuposto básico da teoria Sócio-interacionista é buscar as origens das formas superiores de comportamento consciente, como o pensamento e a memória, nas relações sociais humanas. Também destacam que o homem não é visto somente como um ser passivo ou um produto dessas relações: ele é um ser ativo, que age sobre o mundo que o cerca através das relações sociais e que transforma essas ações a fim de constituir um plano interno. Para Vygotsky, a história da sociedade e o desenvolvimento do homem caminham juntos e estão fortemente interligados.

Desde o nascimento, crianças e adultos estão em interação contínua. Por meio da mediação dos adultos, os processos psicológicos mais complexos tomam forma, inicialmente como processos interpsíquicos e, posteriormente, são internalizados e executados na própria criança, o que determina, portanto, que o desenvolvimento humano está alicerçado sobre o plano das interações: o indivíduo toma para si uma ação que tem, inicialmente, um significado partilhado [9]. O processo de internalização é, então, visto como o mecanismo que intervém no desenvolvimento das funções psicológicas complexas:

"Para Vygotsky, a aprendizagem sempre inclui relações entre as pessoas. A relação do indivíduo com o mundo está sempre mediada pelo outro. Não há como aprender e apreender o mundo se não tivermos o outro, aquele que nos fornece os significados que permitem pensar o mundo a nossa volta. (...) $O$ desenvolvimento não é pensado como algo natural nem mesmo como produto exclusivo da maturação do organismo, mas como um processo em que estão presentes a maturação do organismo, o contato com a cultura produzida pela humanidade $e$ as relações sociais que permitem a aprendizagem. $E$ aí aparece o "outro" como alguém fundamental, pois este outro é quem nos orienta no processo de apropriação da cultura. (...) o desenvolvimento é um processo que se dá de fora para dentro. É no processo de ensino-aprendizagem que ocorre a apropriação da cultura e o conseqüente desenvolvimento do indivíduo" [9 p.124].

Um importante conceito criado por Vygotsky é o da Zona Proximal de Desenvolvimento (ZPD). Como o próprio autor define, a ZPD é " a distância entre o nível de desenvolvimento atual, determinado pela resolução de problema independente e o nível de desenvolvimento potencial determinado através da resolução de problema sob o auxílio do adulto ou em colaboração com colegas mais capazes" [14]. Em outras palavras, a ZPD aponta o que a criança é capaz de aprender sozinha e o que ela é capaz de aprender quando auxiliada e demonstra o importante papel do mediador no aprendizado.

\subsection{4 - A obra de Paulo Freire}

Ainda dentro do contexto das colaborações à teoria construcionista, é necessária uma menção à obra de Paulo Freire.

Freire [8] é contrario ao processo denominado por ele de "modelo bancário de educação". As principais características deste modelo são sintetizadas em Freire [8 p.72]:

"ao educador não cabe nenhum outro papel que não o de disciplinar a entrada do mundo nos educandos. Seu trabalho será, também, o de imitar o mundo. $O$ de ordenar o que já se faz espontaneamente. $O$ de "encher" os educandos de conteúdos. É o de fazer depósitos de "comunicados" - falso saber - que ele considera como verdadeiro saber.”

Segundo o autor, a base da educação é o diálogo. Essa abordagem mostra que todos podem aprender e têm algo a ensinar. Portanto, "não há ignorantes absolutos" [15].

As idéias de Freire mostram ainda que a tarefa de 
educar deve ser muito mais que a mera transferência de conhecimento - ela deve ser um processo de conscientização e testemunho de vida, sem o qual o aluno não poderá descobrir sua identidade cultural e sua responsabilidade na construção de um mundo melhor [16].

Sobre a utilização da informática na educação, Freire [17 p.33] comenta que:

"em lugar de reduzir, pode expandir a capacidade crítica e criativa de nossos meninos $e$ meninas. Depende de quem a usa, a favor de quê e de quem e para quê. $O$ homem concreto deve se instrumentar com os recursos da ciência $e$ da tecnologia para melhor lutar pela causa de sua humanização e de sua libertação".

\subsection{O Construcionismo}

Papert [18 p.127] apresenta o Construcionismo como uma reconstrução pessoal do Construtivismo, que atribui "especial importância ao papel das construções no mundo como um apoio para as construções mentais" e que acredita que o conhecimento é "construído de forma mais virtuosa quando é apoiado pela construção de um tipo mais público no mundo". O autor enxerga o aprendiz como um bricoleur, ou seja, aquele que, dispondo apenas de seu próprio conhecimento e de sua engenhosidade, constrói seu conhecimento quando executa uma determinada tarefa.

Um grande destaque é dado ao aprendizado durante o Período das Operações Concretas. A direta dependência dos símbolos neste processo, normalmente vista com um caráter negativo, é considerada característica fundamental na construção do conhecimento. Papert [18] critica a supervalorização do pensamento abstrato, comumente avaliado como a forma correta do pensar, e acusa os métodos tradicionais de ensino de promoverem a passagem prematura da criança para o Período das Operações Formais, ao mostrar que o raciocínio abstrato e a generalização são exigidos antes mesmo de a criança ter aprendido a lidar com os casos individuais.

Outro autor construcionista, Alan Kay [12], afirma que Papert acredita que a criança é um agente ativo, criador e explorador, e que é intelectualmente muito mais capaz do que é geralmente suposto. Em relação ao
Construcionismo, Kay [12 p.4] comenta:

"Where some people measure progress in answers-right/test or tests-passed/year, we are more interested in "Sistine-Chapel-Ceilings/Lifetime. This is not to say that skill achievement is de-emphasized. "Sistine-Chapel-Ceilings are not gotten without healthy application of both dreaming and great skill at painting those dreams."

Valente [19] destaca que o Construcionismo descreve a construção do conhecimento que ocorre quando um aluno constrói um objeto de seu interesse e que, portanto, duas idéias básicas o diferenciam do Construtivismo: primeiro, pela noção do aprendizado através do fazer, e segundo, pelo fato de o aprendiz estar construindo algo que é de seu interesse e para o qual ele estará motivado. Segundo o autor, a presença do computador contribui para a diferença entre as abordagens construtivistas e construcionistas à construção de conhecimento.

A Figura 1, redesenhada a partir de Valente [19], exibe as contribuições das teorias de Freire, Piaget e Vygotsky no ambiente de aprendizado construcionista.

Conforme Valente [19] expõe, a teoria de Piaget trata da interação entre a criança e o objeto, no caso, o computador, e a teoria de Vygotsky trabalha a interação entre o aprendiz e o mediador do processo de aprendizagem (representado pelo professor). Quanto ao mediador, sua ação é efetiva quando este atua dentro da ZPD, oferecendo ao aprendiz a oportunidade de progredir em uma determinada direção [19].

A teoria de Freire mostra que o aluno está inserido em um contexto social, em uma comunidade, e que o aprendizado não-formal, visto como alternativa à “educação para a domesticação", transmite sua cultura e serve de apoio intelectual [19, 20].

\subsection{1 - Para além do Construcionismo}

O conceito de ambiente de aprendizado construcionista está impregnado de idéias dos pensadores mencionados anteriormente. Ainda que de forma simplificada, nosso objetivo neste texto é apenas indicar um sistema de referências conceituais situando o leitor em tais teorias, que se originam em diferentes disciplinas das ciências humanas. 


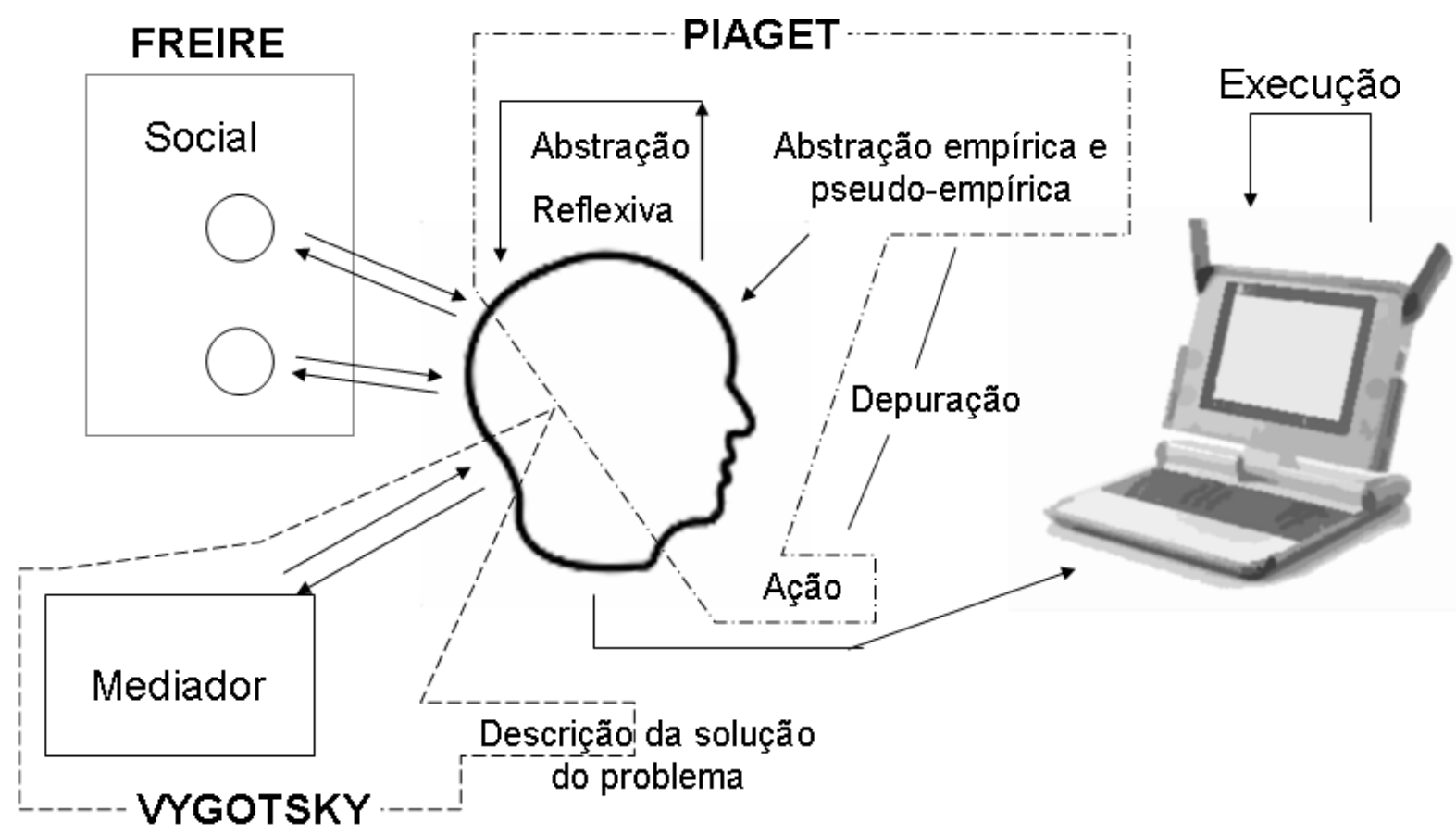

Figura 1 - Contribuições teóricas no Construcionismo [19]

Esse referencial está associado a outros movimentos contemporâneos como por exemplo o construtivismo social e a teoria da complexidade, para citar alguns. O Construtivismo Social é um conceito discutido entre historiadores, filósofos, e sociólogos da ciência no qual teorias científicas são moldadas por seus contextos políticos e sociais [21]. A necessidade do pensamento complexo é estudada por Edgar Morin [22], que o entende como "o tecido de acontecimentos, ações, interações, retroações, determinações, acasos, que constituem nosso mundo fenomênico". Tais propostas teóricas se reportam aos princípios conceituais da filosofia pós-moderna, a saber: crítica ao acesso possível a uma realidade independente do indivíduo, rejeição de um enfoque cartesiano de investigação científica fundado no rigor e na objetividade [23].

Essa nova maneira de enxergar o mundo e nossa relação com o conhecimento tem reflexos no design e desenvolvimento de tecnologia. Enquanto o objetivismo assume uma única realidade e explica diferenças de idéias como aberrações, o subjetivismo trata diferentes idéias dos indivíduos como pontos de partida para uma realidade compartilhada [24]. A visão subjetivista enfatiza as habilidades dos indivíduos, sua liberdade em escolher fluxos de ações, responsabilidades morais para suas escolhas, e as incertezas, novidades e estados emocionais que carregam.

\subsection{Paradigmas de softwares educacionais}

Esta seção analisa e classifica o software educacional com base no paradigma educacional subjacente. Para definir a posição da ferramenta proposta no conjunto de categorias de aplicações educacionais, buscou-se entender o funcionamento de aplicações similares. Para tal, foram utilizadas duas categorias de classificação possíveis: classificação quanto ao tipo de software educacional e classificação quanto ao ambiente de aprendizado baseado no computador que esse software constitui. Esta análise é discutida na Seção 4, na qual é apresentada a concepção da aplicação.

A primeira classificação é realizada segundo Valente [27]. Os softwares são analisados em sete categorias: Tutoriais, Programação, Processadores de Texto, Uso de Multimídia e de Internet, Desenvolvimento de Multimídia e Internet, Simulação e Modelagem e Jogos.

A segunda classificação é obtida de Baranauskas et al. [28]. Os ambientes são analisados em três categorias principais: Ensino Assistido por Computador, Aprendizado Socialmente Distribuído e Ambientes Interativos de Aprendizagem, que, por sua vez, abrange modelagem e simulação, ambientes de programação, micromundos e sistemas de autoria. 
Outras taxonomias para software educacional podem ser encontradas em [25 ] e [26].

Em nossa visão, o Construcionismo de Papert norteia todo o ambiente de utilização de um laptop em sala de aula e determina os aspectos principais a serem levados em conta no projeto de toda e qualquer atividade envolvendo esta proposta.

Assim, uma aplicação para o XO deve priorizar a construção do conhecimento realizada pelo aluno. Levando em conta o público-alvo para este tipo de aparelho, alunos situados na faixa etária a partir do Período de Operações Concretas, faz-se necessário incentivar o trabalho em equipe e a colaboração, buscando, também, fornecer o apoio simbólico que sustente o raciocínio.

Outros dois importantes pontos a serem considerados no desenvolvimento de um software no âmbito do projeto OLPC são o papel do professor e a relação social da atividade executada. Segundo o modelo estudado, o professor é aquele que apoiará a utilização do Caderno Digital com o intuito de tornar concreto o potencial aprendizado do aluno. Considerações a respeito do contexto de uso devem partir também da análise de como ocorre o diálogo entre a tarefa a ser executada na ferramenta e a sociedade, que representa os agentes externos no processo em questão.

\section{Novos caminhos para a educação brasileira}

O sistema formal de educação brasileiro, de modo geral, tem raízes no "modelo bancário" discutido em Freire [8] ou ainda no "Instrucionismo", segundo Papert [18]. Ambas as denominações apontam as mesmas características: o conhecimento é dividido em disciplinas que apresentam pouca ou nenhuma conexão, separado em pequenos “compartimentos" [18] e "depositado" pelo educador na mente dos educandos [8]. Ainda segundo Papert [18], este modelo de educação acredita que "a via para a melhor aprendizagem deve ser o aperfeiçoamento da instrução" e que para transmitir conhecimento deve-se falar sobre o conhecimento.

No período de pouco mais de uma década, presenciou-se uma Revolução da Informação e novas tecnologias criaram novos espaços de conhecimento: além da escola, as empresas, o espaço domiciliar e o social podem ser considerados espaços educativos [29].

"Cada dia mais pessoas estudam em casa, pois podem, de casa, acessar o ciberespaço da formação e da aprendizagem a distância, buscar "fora" - a informação disponível nas redes de computadores interligados - serviços que respondem às suas demandas de conhecimento. Por outro lado, a sociedade civil (ONGs, associações, sindicatos, igrejas, etc.) está se fortalecendo não apenas como espaço de trabalho, em muitos casos, voluntário, mas também como espaço de difusão de conhecimentos e de formação continuada. É um espaço potencializado pelas novas tecnologias, inovando constantemente nas metodologias." [29 p.7]

Apesar da intensidade destas mudanças ocorridas na sociedade, a escola apresenta respostas lentas e, muitas vezes, controversas. Valente [30] mostra como a tentativa de informatização das escolas, dada pela inserção de disciplinas de computação na grade curricular, ou "alfabetização em informática", preparam um profissional obsoleto, incapaz de enfrentar as mudanças pelas quais a sociedade passa.

Frente a este panorama, ao qual a educação brasileira dá sinais de incapacidade de acompanhar seu rápido progresso e transformação, Gadotti [29 p.8] aponta qual deve ser o papel da escola na Sociedade da Informação:

" a escola deve servir de bússola para navegar nesse mar do conhecimento, superando a visão utilitarista de só oferecer informações "úteis" para a competitividade, para obter resultados.(...) Significa orientar criticamente, sobretudo as crianças e jovens, na busca de uma informação que os faça crescer e não embrutecer.”

É neste contexto, no qual o conhecimento pode utilizar de fontes outras além da escola, que está inserida a proposta da OLPC. O laptop poderá ser um valioso canal de construção de conhecimentos, permitindo ao aluno ter acesso, virtualmente, ao conteúdo que desejar e aprender o que lhe interessa. E neste ponto o educador retoma seu papel, degradado nas últimas décadas, de intermediador e facilitador do processo de construção do aprendiz.

O Caderno Digital encontra sua justificativa neste novo paradigma da educação, intermediando a colaboração entre os próprios educandos e a comunicação entre estes e os educadores no que tange a produções de textos. Sua função consiste em apoiar o diálogo entre os atores do processo educativo, provendo uma forma extra-textual de comunicação, por meio de símbolos e anotações offline. 


\section{O Caderno Digital: elementos de design e fundamentação teórica}

O primeiro passo da concepção do Caderno Digital consistiu em reconhecer o papel da ferramenta dentro do contexto de aplicações educacionais e seus paradigmas de uso.

\subsection{Concepção}

Seguindo a classificação de Valente [27] para softwares educacionais, o Caderno Digital pode ser primariamente enquadrado na categoria de Processadores de Texto. Entretanto, o suporte à inserção de imagens, sons e vídeos bem como o módulo de anotações permitem considerar certas características da categoria de Desenvolvimento de Multimídia e Internet.

Valente [27] analisa ambas as categorias segundo o ciclo descrição-execução-reflexão-depuraçãodescrição. O idioma natural e os comandos de formatação do processador fornecem a interação com o usuário. Valente [27] aponta que tais ferramentas executam a formatação, respondendo à descrição estrutural do texto, mas não são capazes de executar o conteúdo da informação, processando a qualidade das informações e fornecendo feedback ao utilizador, o que inviabiliza processos fiéis de reflexão e depuração. Nesse sentido, as duas categorias apresentam o aspecto de execução bastante parecido. Valente [27] então conclui que, utilizado dessa forma, o computador não provê informações necessárias para o aprendiz avaliar seu nível de conhecimento a fim de alcançar níveis mais complexos de compreensão e conceituação e, portanto, os processadores de texto e ferramentas de desenvolvimento multimídia não apresentam características que auxiliam a construção do conhecimento e compreensão de idéias. A Figura 2, redesenhada a partir de Valente [27], esquematiza a ocorrência dos processos mentais durante a utilização de processadores de texto.

A classificação proposta por Baranauskas et al. [28] insere o Caderno Digital na classe dos Ambientes Interativos de Aprendizagem, que são caracterizados, sobretudo, por permitir que o estudante, e não o sistema, tenha o controle do processo e por priorizar a construção do conhecimento pelo aluno diferentemente dos métodos de instrução. Dentro dessa categoria, a ferramenta proposta apresenta algumas características da classe dos Sistemas de Autoria, embora não atenda integralmente ao comportamento observado para esta

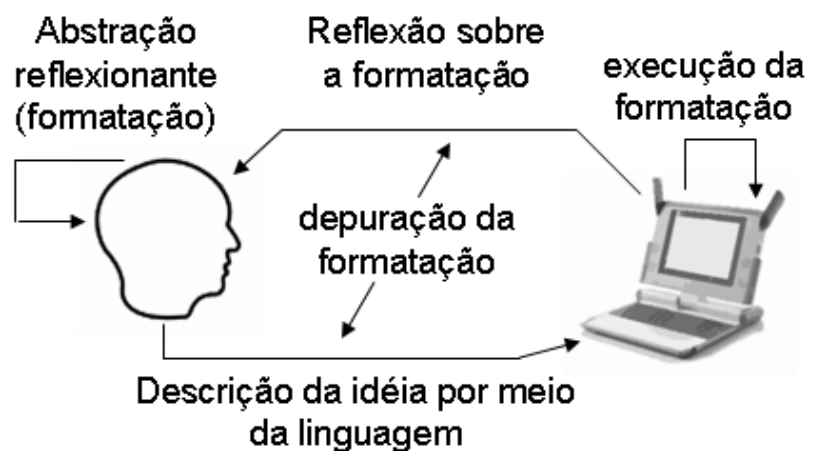

Figura 2 - Interação aprendiz-computador usando um processador de textos [27]

classe.

Com base nas observações do papel dos editores de texto no conjunto dos softwares educacionais, pode-se observar que estas ferramentas carecem da capacidade de avaliar a produção do aluno e fornecer uma resposta que o permita avaliar criticamente sua criação. $O$ aprendiz tem o controle sobre o processo, mas não recebe indicações que promovam seu processo de reflexão e o façam aprimorar e construir seu conhecimento.

Sendo assim, a deficiência dos editores de texto enquanto ferramenta educacional só será solucionada quando houver um software com capacidade de avaliação de conteúdos textuais de forma complexa, à semelhança da atividade exercida pelo educador neste contexto.

A proposta do Caderno Digital foca neste ponto ao projetar uma ferramenta que, ainda que não exclua a tarefa humana de processar e avaliar o texto, atua como facilitador desta atividade, apoiando e estruturando os passos da avaliação. Isto é observado se considerarmos o cenário de uso em que o educador utiliza a ferramenta para avaliar a produção de um aluno sem modificá-la mas destacando elementos sobre os quais o educando poderá refletir, julgar e realizar alterações.

Diante desta abordagem diferenciada para uma ferramenta de edição de textos, e levando em conta o estágio ainda inicial de produção de aplicações para a plataforma do $\mathrm{XO}$, que conta com um conjunto relativamente pequeno de aplicações disponíveis, podese afirmar que o Caderno Digital representa uma iniciativa pioneira de potencial utilidade.

\subsection{Metáfora e Interface Gráfica de Usuário}

Seguindo o nome proposto para a aplicação e utilizando os padrões visuais do editor de texto já presente nas distribuições do XO, a ferramenta busca 
apresentar-se para o aluno sob a metáfora de um caderno. Isto se deve principalmente à função de permitir ao usuário realizar livres anotações e marcações sobre um texto, função muito presente no cotidiano escolar, mas comumente ausente em editores de texto. Aliar a versatilidade de um artefato como o caderno a um ambiente de leitura e edição de textos, sem, contudo, sobrecarregar a interface de usuário, foi o principal objetivo da construção da interface desta ferramenta.

Fruto de ponderação entre a necessidade de exibir de forma explícita as principais funcionalidades, clareza e concisão do layout, metáfora escolhida e exigências de hardware e software, a interface de usuário foi

Seguindo o padrão das aplicações desenvolvidas pela OLPC, o Caderno Digital apresenta recursos de ajuda ao usuário bastante imediatos, implementados diretamente pela utilização de tooltips, que são breves descrições da função de cada botão exibidas quando o usuário posiciona o ponteiro do mouse sobre o botão, evitando extensos documentos de ajuda que poderiam entediar a criança durante o aprendizado de uso da ferramenta.

\section{Aspectos de projeto e implementação}

Esta seção trata das decisões técnicas e questões diretamente relacionadas ao desenvolvimento da ferramenta.

Para o projeto da ferramenta foi adotado um modelo simplificado de Engenharia de Software visando obter informações específicas sobre as funcionalidades, comportamento do sistema e interação com o usuário, além de possibilitar a documentação do processo de desenvolvimento. Tal processo consistiu na elaboração de cenários de utilização e documento de visão, avaliação de ferramentas afins, identificação de metas de usuário e, por fim, modelagem dos casos de uso. Maiores detalhes referentes ao projeto do software e sua implementação poderão ser obtidos na página do projeto, hospedada pelo Google Code, em http://code.google.com/p/cadernodigital/.

Tanto os fundamentos teóricos estudados na revisão bibliográfica quanto os requisitos identificados no processo de Engenharia de Software influenciaram nas decisões de implementação. Os principais aspectos referentes ao desenvolvimento do software são expostos nos sub-tópicos a seguir. construída priorizando o espaço de trabalho, ou canvas, optando por exibir uma barra de ferramentas minimalista. Na Figura 3 são exibidas as telas referentes aos dois modos de operação do sistema: modo de Produção, à esquerda, no qual o texto é editado, e modo de Folha de Anotações, à direita, no qual são inseridas figuras e anotações sobre o texto.

A alternância entre os modos é ativada pelo botão com fundo alaranjado que sugere uma folha com anotações coloridas. Buscou-se a distinção imediata entre os modos através das cores dos ícones na barra de ferramentas: a cor alaranjada predominante na barra da figura à direita indica que o usuário utiliza a Folha de Anotações.

\subsection{Linguagem, dependências e formatos de arquivos}

$\mathrm{O}$ sistema utilizado no XO oferece cinco ambientes de programação: Python, Javascript, CSound, Squeak e Logo. De todas elas, Python é a única alternativa que oferece os recursos necessários para o desenvolvimento da aplicação e alia a vantagem de possuir uma vasta biblioteca já implementada.

A interface gráfica foi desenvolvida utilizando a biblioteca GTK+ 2.0, manipulável em Python através da language binding PyGtk 2.10, ambas pré-instaladas na máquina $\mathrm{XO}$.

Ferramentas com finalidades diversas estão incluídas nas distribuições oferecidas pela OLPC para o laptop. Entre elas está uma bem-sucedida adaptação do editor de textos opensource AbiWord denominada Write. Esta ferramenta utiliza o AbiWidget, um widget GTK que provê um canvas de edição de texto rico em recursos. Tal widget é manipulável em Python através da utilização do módulo PyAbiWord.

Tendo em vista a facilidade de instalação futura do Caderno Digital, obtida pela utilização de bibliotecas nativas ao sistema, e também o reuso de código e aceleração da produção da ferramenta, a aplicação foi desenvolvida utilizando o AbiWidget para o controle das operações básicas de edição de texto, como formatação e alinhamento da fonte, enquanto as operações de desenho e anotações foram integralmente desenvolvidas durante o projeto.

Os formatos de arquivo de texto suportados pela ferramenta incluem 'plain text', 'rich-text format' (RTF), HTML e o padrão de textos 'abw', do editor AbiWord.

Para armazenar os dados das folhas de anotações, 


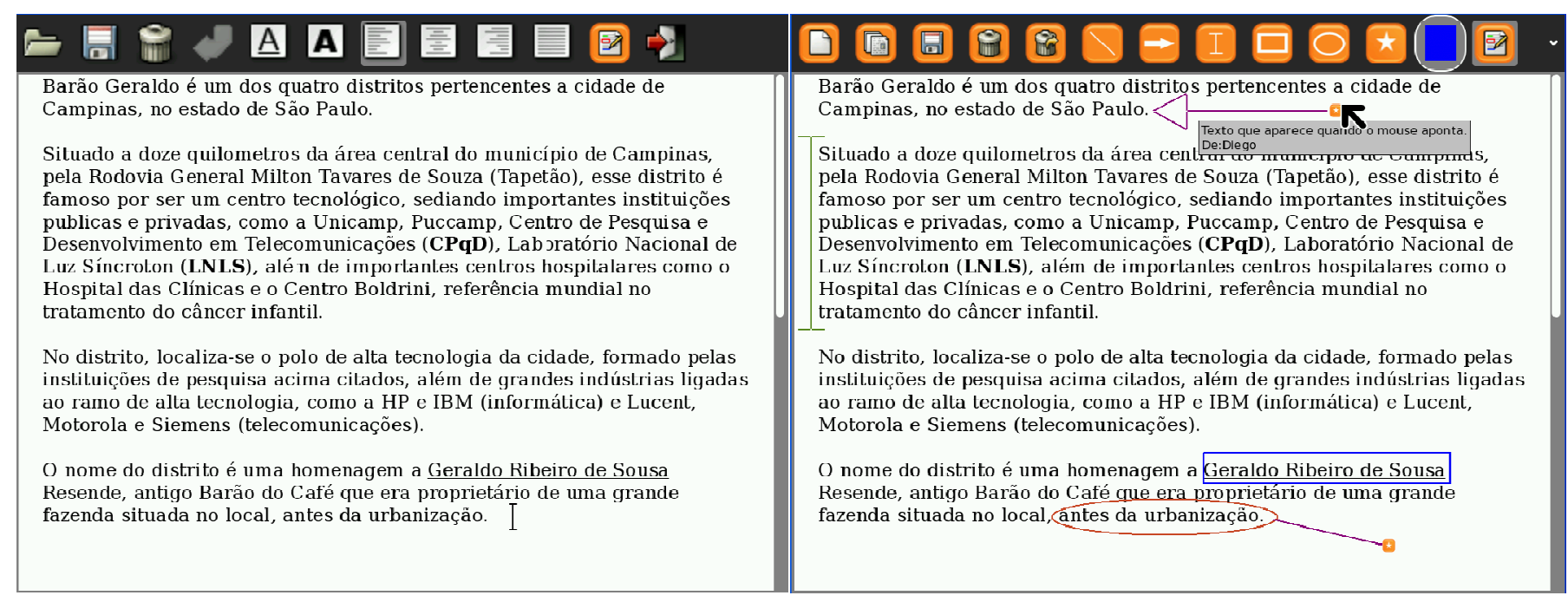

Figura 3 - Modos de operação do sistema: Produção, à esquerda, e Folha de Anotações, à direita

foi definido um formato próprio, identificado pela extensão '.cda', que utiliza uma estrutura de tags baseadas em XML.

\subsection{Ambiente de desenvolvimento, portabilidade e licença de uso}

A fim de proporcionar compatibilidade com as versões então recentes do XO e usufruir das bibliotecas mais recentes, a aplicação foi desenvolvida e testada em um ambiente de emulação, utilizando a imagem da distribuição de desenvolvimento número 1883 ('xo-1olpc-stream-joyride-build-1883-20080418_1950devel_ext3.img'), executada no software QEMU 0.9.1.

Durante a execução do projeto, alguns acontecimentos modificaram o panorama da utilização dos laptops educacionais no Brasil: surgiram propostas de outras organizações além da OLPC e estabeleceu-se uma indefinição sobre a futura adoção de máquinas deste tipo pelo governo nacional. Sem perder o foco no projeto, mas preocupando-se com a possível portabilidade do software, buscou-se codificar a ferramenta de forma mais independente com relação à plataforma oferecida pelo XO. Em termos de codificação, isso significou que a aplicação não fez uso das classes de atividade fornecidas pelo Sugar, exclusiva do XO, optando por construir seus objetos gráficos inteiramente sobre as classes GTK.

Para preservar os direitos de código aberto da ferramenta, o software é produzido e será distribuído sob a licença GNU General Public License v2.0 [31].

\subsection{Funcionalidades disponíveis}

As funcionalidades referentes à edição do texto são tratadas pelo AbiWidget, que oferece uma completa gama de recursos de formatação de texto, como escolha de tipo, tamanho, cor e estilo de fonte, alinhamento de parágrafos e inserção de imagens.

Com relação às funcionalidades de anotação, foram implementadas cinco ferramentas de desenho: linha, seta, delimitador, retângulo e elipse; além de um seletor de cores. A Figura 4 exibe a parte da barra de ferramentas que contém as funcionalidades de desenho, enquanto a Figura 5 mostra algumas formas desenhadas com cada uma.

Tendo em vista a limitação imposta à tarefa de arrastar pelo touchpad do laptop XO, no qual o arraste é realizado mantendo pressionado o botão com um dedo enquanto outro dedo realiza a rolagem, estas cinco ferramentas permitem ao usuário criar as figuras com apenas dois cliques, que marcam os vértices superior esquerdo e inferior direito do retângulo que contém a figura.

Ainda referente às funcionalidades de anotação, foi implementada uma sexta ferramenta, denominada Ponto de Anotação. Esta ferramenta consiste em posicionar na Folha de Anotações um pequeno ícone representando uma estrela. Ao posicionar o ponteiro sobre este ícone, é exibido um texto configurável por duplo clique. Dessa forma, uma anotação textual pode ser realizada sem que a visualização fique sobrecarregada com sobreposição de diferentes textos, mostrando informações adicionais apenas quando solicitado. A Figura 6 exemplifica a operação de edição do texto referente a um Ponto de Anotação. 


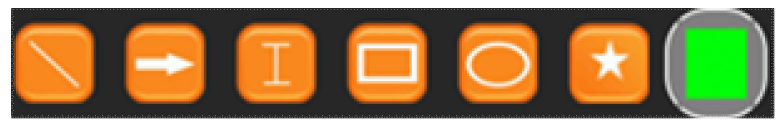

Figura 4 - Funcionalidades de desenho

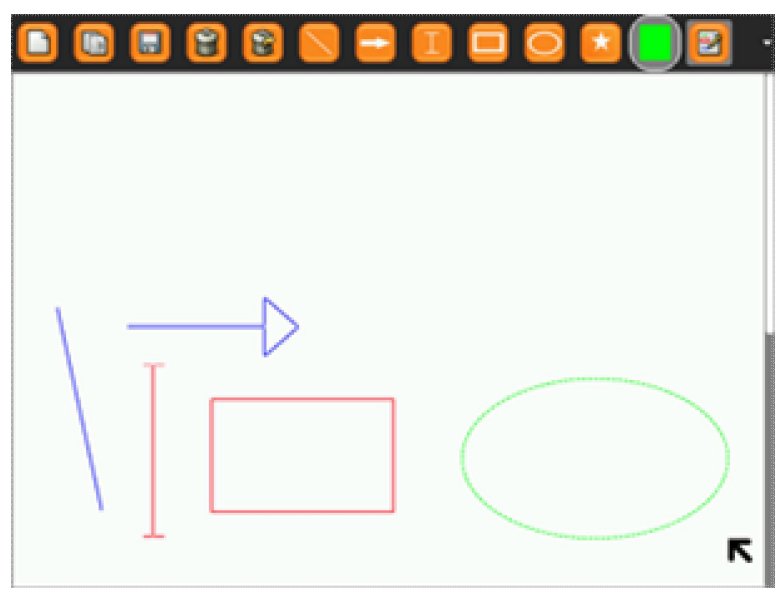

Figura 5 - Formas desenhadas

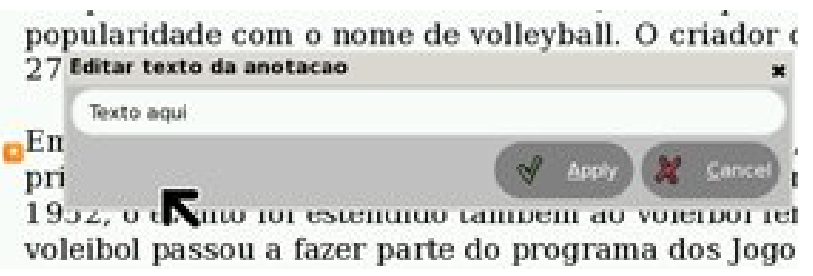

Figura 6 - Edição do texto de Ponto de Anotação

\subsection{Manipulação de anotações}

Ao realizar a mudança para o modo de Anotações, o software coleta uma informação do estado atual do editor do texto, congelando-o em um buffer de exibição que é inserido em um container de objetos gráficos, o gtk.Layout. Quando uma nova anotação é inserida, um objeto gtk.Image é gerado, a partir de um buffer de exibição sobre o qual a anotação foi desenhada, e inserido no gtk.Layout. A fim de permitir a exclusão individual de anotações por duplo clique com o botão direito, as gtk.Image são inseridas em objetos gtk.EventBox, que fornecem a possibilidade de captura de eventos realizados pelo ponteiro sobre a figura.

Duas pilhas de referências às anotações são utilizadas durante a execução da aplicação: uma pilha de anotações válidas e uma pilha contendo anotações excluídas. Tal característica possibilita a implementação de funcionalidades simplificadas de 'desfazer' e 'refazer'. A invocação da primeira fará com que a última anotação inserida seja apagada na tela e colocada na pilha de anotações excluídas, enquanto a invocação da segunda fará a última anotação apagada retornar à tela.

\subsection{Preview dinâmico de figuras}

Esta funcionalidade proporciona ao usuário poder visualizar como ficará a figura que ele está para inserir. Ao selecionar uma ferramenta de desenho e clicar sobre o canvas, a posição inicial da figura é marcada. A partir deste momento, qualquer evento de deslocamento do ponteiro irá invocar um método de desenho da anotação escolhida partindo do ponto inicial e utilizando a posição atual do ponteiro como ponto final. Para diferenciar as figuras de preview das demais figuras já inseridas, optou-se por desenhar as primeiras apenas com linhas tracejadas. A Figura 7 exibe um zoom de uma elipse durante o processo desenho.

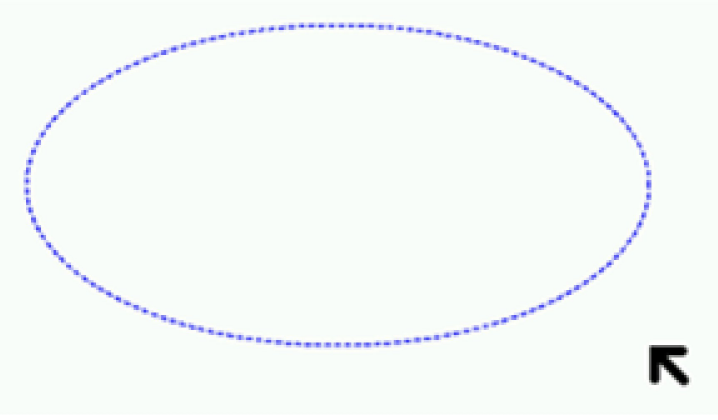

Figura 7 - Preview do desenho de uma elipse

\section{6. 'Abrir', 'salvar' e 'combinar' folhas de anotações}

Foram também implementados os recursos de trabalhar com Folhas de Anotações em arquivo.

A funcionalidade de 'Salvar Folha de Anotação' armazena em um arquivo de nome escolhido todas as anotações da Folha atual. Para cada figura é criada uma tag ' $\langle$ fig $>$ ' descrevendo o tipo da figura, a cor e as coordenadas. A tag ' $\langle$ pto〉' indica um ponto de anotação e seus atributos descrevem seu texto e sua posição.

O recurso de 'Abrir Folha de Anotação' carrega na tela todas as anotações contidas no arquivo. A cada figura inserida, uma tooltip é associada a fim de indicar sua origem, que é dada pelo nome do arquivo que a contém. Ao contrário do que é comumente realizado no carregamento de documentos em arquivo nas demais aplicações, 'Abrir Folha de Anotações' no Caderno Digital é uma operação aditiva, ou seja, as anotações exibidas na tela antes da operação são mantidas enquanto as novas, referentes ao arquivo, são inseridas. Dessa forma, torna-se útil associar a cada anotação sua 
origem. Estas características permitem ao usuário combinar variadas Folhas de Anotações, promovendo e facilitando o ambiente colaborativo defendido pela OLPC. A Figura 8 exemplifica a identificação da origem de uma anotação combinada à folha atual.

A fim de evitar ambigüidades, a operação 'Abrir Folha de Anotações' é descrita na aplicação como 'Adicionar Folha de Anotações', e uma outra funcionalidade, denominada 'Nova Folha de Anotações', foi implementada com o propósito de limpar a tela.

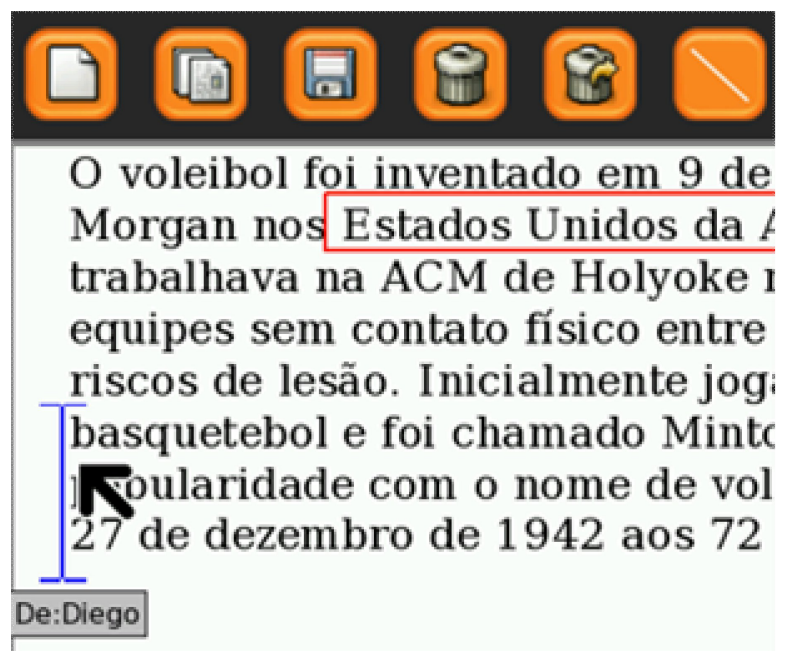

Figura 8 - Identificação de uma anotação combinada à folha atual

\section{Testes preliminares com usuários}

Com a intenção de realizar uma primeira avaliação sobre o direcionamento dado ao desenvolvimento, foram realizados testes preliminares com usuários. Nesta etapa buscou-se avaliar principalmente se a metáfora proposta é compreendida pelo usuário e a facilidade de uso do sistema. Para tal, foram convidados a participar do teste quatro sujeitos, entre 11 e 15 anos. Cada teste foi realizado mediante a assinatura de um Termo de Consentimento Livre e Esclarecido por parte do responsável de cada sujeito.

Os testes foram realizados com o software Caderno Digital sendo executado no laptop $\mathrm{XO}$, de propriedade do Instituto de Computação da UNICAMP.

A metodologia utilizada consistiu em iniciar o teste com uma breve apresentação oral da aplicação e, em seguida, permitir ao sujeito utilizá-la livremente por cerca de dez minutos. Na seqüência, carregou-se um texto pequeno, de conteúdo diversificado, e foi solicitado ao sujeito realizar anotações quaisquer sobre o documento. Por fim, encerrou-se o uso da aplicação e o sujeito respondeu a questionário contendo os seguintes tópicos:

- "Do que mais gostou" e "do que não gostou".

- Uma nota de zero a cinco para a facilidade de aprendizagem, explicada ao sujeito como a facilidade que ele encontrou para realizar alguma atividade desejada, como traçar uma linha, pela primeira vez.

- Uma nota de zero a cinco para a facilidade de uso, explicada ao sujeito como a facilidade que ele encontrou para realizar alguma atividade desejada após já ter aprendido como fazê-la.

- Comentários, críticas ou sugestões.

A Figura 9 exibe algumas capturas de tela realizadas e fotos tiradas durante os testes.

Todos os sujeitos submetidos ao teste identificaram de forma correta o propósito da aplicação e mencionaram semelhanças com o uso de um caderno. Outro ponto comum bastante citado refere-se à ferramenta ponto de anotação, destacada como o aspecto que mais gostaram pela praticidade e "economia de espaço" quando comparada com as “anotações de canto de folha no caderno". Os pontos que mais desagradaram os sujeitos foram apontados como a limitação do desenho da seta às direções horizontal e vertical, dificuldade para excluir linhas e setas em algumas situações e o desconforto na utilização do touchpad e teclado do XO.

Com relação às notas para facilidade de aprendizagem e facilidade de uso, ambas obtiveram média 4 (para notas entre zero e cinco).

Os comentários, sugestões e críticas apresentaram conteúdo variado. De modo geral, os sujeitos sugeriram novos recursos, dentre os quais se destacam a seleção de espessura da linha e preenchimento de desenho, uma ferramenta que imite uma caneta marca-textos e a possibilidade de arrastar as anotações pela folha. A inclusão de novas funcionalidades, entretanto, depende de uma análise mais ampla e rigorosa, especialmente considerando usuários de faixas etárias e graus de familiaridade com a tecnologia digital inferiores às dos sujeitos do teste.

Com os resultados obtidos nos testes, foi possível verificar que a aplicação desenvolvida neste projeto potencialmente possui utilidade real e que a metáfora 

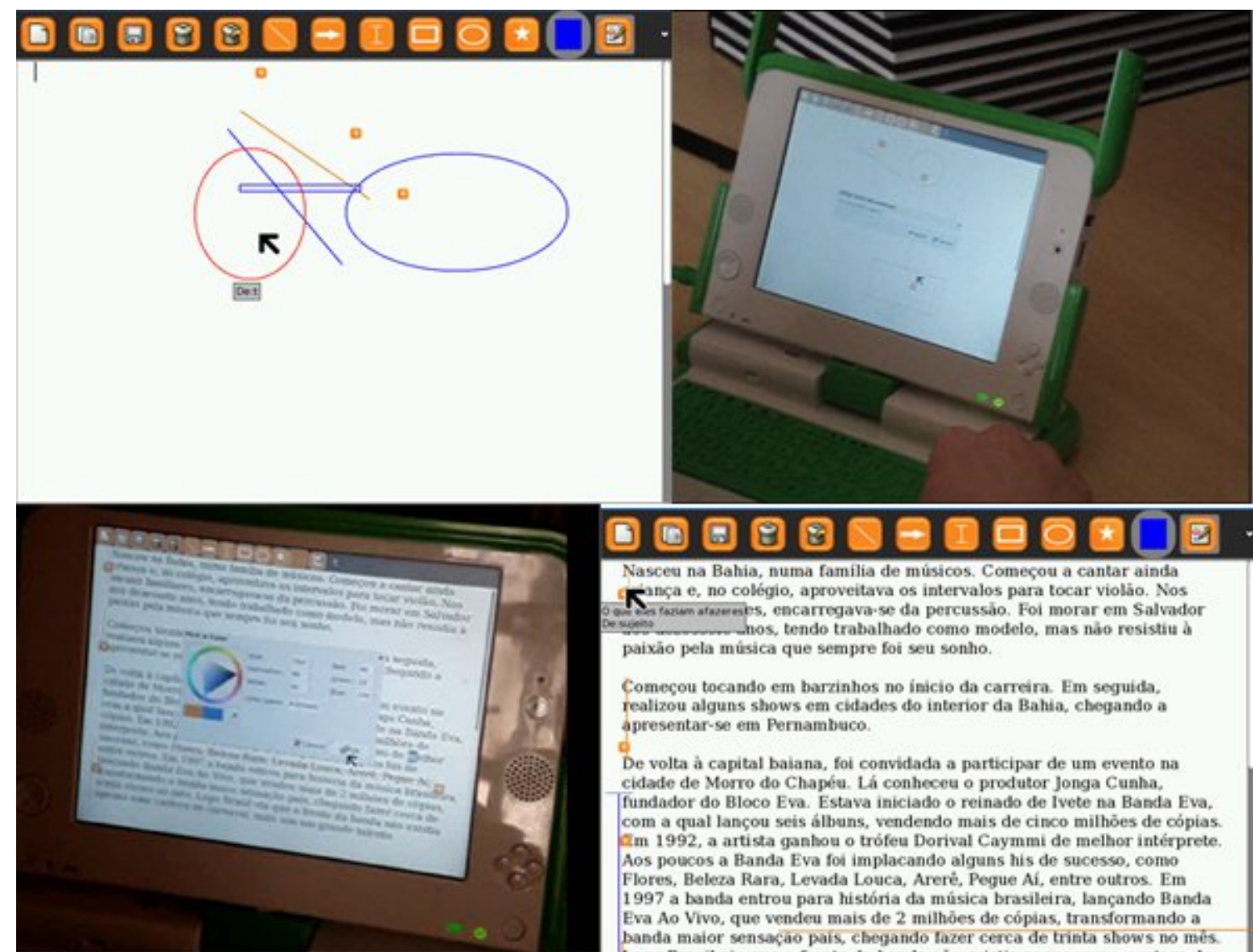

Nasceu na Bahia, numa familia de músicos. Começou a cantar ainda Tança e, no colégio, aproveitava os intervalos para tocar violáo. Nos K velnos, tendo trabalhado como modelo, mas nảo resistiu à paixáo pela música que sempre foi seu sonho.

Começou tocando em barzinhos no ínicio da carreira. Em seguida. realizou alguns shows $\mathrm{em}$ cidades do interior da Bahia, chogando a apresentar-se em Pernambuco.

De volta à capital baiana, foi convidada a participar de um evento na cidade de Morro do Chapéu. La conheceru o produtor Jonga Cunha, fundador do Bloco Eva. Estava iniciado o reinado de lvete na Banda Eva, com a qual lançou seis álbuns, vendendo mais de cinco milhỏes de cópias. $\sigma_{m}$ 1992, a artista ganbou o trófeu Dorival Caymmi de melhor intérprete. Aos poucos a Banda Eva fol implacando alguas his de sucesso, como Flores, Beleza Rara, Levada Louca, Areré, Pegue Ai, entre outros. Em
1997 a banda entrou para histónia da música brasileira, lançando Banda 1997 a banda entrou para história da música brasileira, lançando Bandas
Eva Ao Vivo, que vendeu mais de 2 milhōes de cópias, transformando a banda maior sensaçao pais, ctregando lazer cerca de trista shows no més. Logo Brasil viu que a frente da banda náo existia apenas uma cantora de carnaval, mais sim um grande talento.

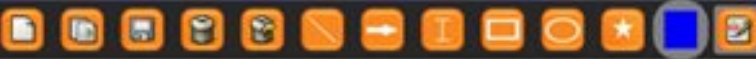
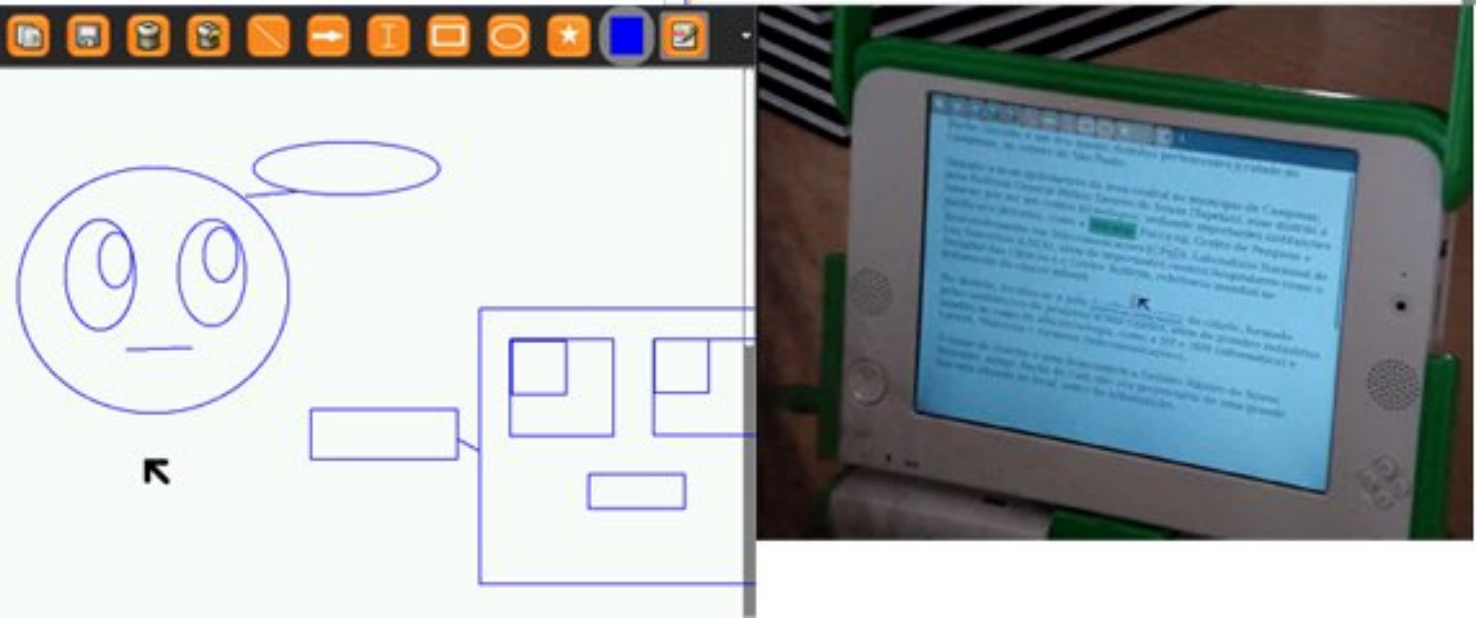

Figura 9 - Algumas fotos e capturas de tela realizadas durante os testes 
proposta foi apreendida. Os testes também permitiram observar a usabilidade do sistema, característica que, ainda que não implique sozinha no sucesso pedagógico da ferramenta, é uma condição necessária para tal.

Vale destacar que os testes foram executados considerando a utilização individual em situação de laboratório. Em um ambiente escolar real, cada usuário interage com os outros ao seu redor, multiplicando as possibilidades de uso.

As anotações gráficas sobre um texto dado poderiam ser repassadas a um companheiro com a finalidade de mostrar a ele o que se considerou relevante em um determinado texto. Ou, ainda, combinar as de outros companheiros com as próprias anotações a fim de descobrir elementos do texto aos quais não se havia dado a devida importância.

Considerando a produção de textos pelos alunos, as anotações podem servir como ferramenta de discussão entre o autor e seus companheiros, que destacariam, entre outros, os pontos polêmicos. Ou mesmo como ferramenta de correção, levando em conta que o educador pode realizar anotações sobre o texto sem alterá-lo, fornecendo o desejável feedback ao aluno. Ambos os cenários completam o ciclo descrito por Valente [27], possibilitando ao aprendiz produzir e, com base em respostas de avaliação, refinar sua criação e aprender. Dessa maneira, podemos dizer que a ferramenta desenvolvida potencializa a proposta construcionista de seu uso em contexto educacional.

A avaliação preliminar realizada mostrou a relação de interação cíclica aprendiz-ferramenta sustentada pela funcionalidade disponibilizada bem como sua expressão na interface. Certamente esta avaliação da ferramenta em situação de laboratório, embora demonstre a sua viabilidade operacional e inteligibilidade aos sujeitos do teste, não prescinde de um estudo de caso em situações reais de uso na escola, com o envolvimento das outras partes interessadas, entre elas o professor, e consideração das condições de acesso dos alunos e das escolas à tecnologia de forma geral. O papel do professor como articulador das potencialidades viabilizadas pela ferramenta e a relação social da atividade executada localmente pelo aluno e seu impacto educacional mais amplo constituem um cenário muito mais complexo para o qual este trabalho pode ser um ponto de partida.

\section{Conclusão}

Novas tecnologias computacionais têm criado novos espaços de conhecimento para além da escola formal.
Este trabalho revisita as principais teorias educacionais que fundamentam o uso de computadores em educação e propõe uma ferramenta alinhada à proposta da OLPC para uso educacional de laptops de baixo custo. $\mathrm{O}$ artigo apresenta e discute as etapas de concepção, projeto e desenvolvimento do Caderno Digital.

O estudo bibliográfico forneceu os subsídios necessários à compreensão da proposta de utilização dos laptops na educação, entendendo seu papel, além de proporcionar bases para as decisões de design do software de modo a mantê-lo consistente com a proposta educacional subjacente.

Quanto à aplicação, seu desenvolvimento atingiu o estágio esperado para uso inicial. Os testes puderam comprovar sua rápida assimilação por novos usuários e sua potencial utilidade em práticas educativas, devido, sobretudo, ao recurso de permitir ao aluno destacar pontos-chave, sintetizar sua compreensão e poder compartilhar sua visão com outros. Os testes também indicaram novas funcionalidades que podem ser incorporadas incrementalmente rumo a uma versão mais completa da ferramenta. A partir do estágio atual, o software poderá ser estendido de forma a agregar não somente tais funcionalidades, mas também outras, provindas de colaboradores diversos, uma vez que o projeto está hospedado em uma plataforma de incentivo ao código livre e à colaboração.

\section{Agradecimentos}

Os autores agradecem ao editor e referees anônimos da RBIE, aos sujeitos e colaboradores dos testes, ao Prof. J.A. Valente pela disponibilização do laptop XO e à Mariana Bahia pelo suporte durante o projeto. Agradecemos também ao CNPq pelo apoio financeiro.

\section{Referências}

\begin{tabular}{|c|l|}
\hline$[1]$ & $\begin{array}{l}\text { OLPC, One Laptop per Child, } \\
\text { http://wiki.laptop.org/go/One_Laptop_per }\end{array}$ \\
\hline Child, acesso em 05 jun. 2009. \\
\hline [2] & $\begin{array}{l}\text { S.M. Papert. Mindstorms: Children, } \\
\text { Computers, and Powerful Ideas. New York, } \\
\text { Basic Books, 1980. }\end{array}$ \\
\hline [3] & $\begin{array}{l}\text { OLPC, Software Components, } \\
\text { http://wiki.laptop.org/go/One_Laptop_per }\end{array}$ \\
\hline $\begin{array}{l}\text { Child, acesso em 05 jun. 2009. } \\
\text { K.L. Kraemer et al. One laptop per child: } \\
\text { vision vs. reality. Commun. ACM, 2009. p. } \\
\text { 66-73. }\end{array}$ \\
\hline
\end{tabular}




\begin{tabular}{|c|c|}
\hline [5] & $\begin{array}{l}\text { P. Hourcade et al. Early olpc experiences in } \\
\text { a rural uruguayan school. CHI ' } 08 \text {. ACM, } \\
\text { New York, NY, } 2008 \text {. }\end{array}$ \\
\hline [6] & $\begin{array}{l}\text { J. Piaget. A Epistemologia Genética. } \\
\text { Petrópolis, RJ, Vozes, } 1971 .\end{array}$ \\
\hline [7] & $\begin{array}{l}\text { L.S. Vygotsky. Mind in society: } \\
\text { development of higher psychological } \\
\text { processes. Harvard University Press, } \\
\text { Cambridge, Massachusetts, } 1978 .\end{array}$ \\
\hline [8] & $\begin{array}{l}\text { P. Freire. Pedagogia do oprimido. 4.ed. Rio } \\
\text { de Janeiro, Paz e Terra, } 1977 .\end{array}$ \\
\hline [9] & $\begin{array}{l}\text { A.B. Bock et al. Psicologias - uma } \\
\text { introdução ao estudo de psicologia. 13.ed. } \\
\text { São Paulo, Saraiva, } 1999 \text {, cap. } 7 \text { e } 8 \text {. }\end{array}$ \\
\hline$[10]$ & $\begin{array}{l}\text { H.G. Furth. Piaget na sala de aula. Rio de } \\
\text { Janeiro, Forense Universitária, } 1972 .\end{array}$ \\
\hline [11] & $\begin{array}{l}\text { J. Piaget. Seis estudos de psicologia. Rio de } \\
\text { Janeiro, Forense Universitária, } 1967 .\end{array}$ \\
\hline [12] & $\begin{array}{l}\text { A. Kay. A personal computer for children } \\
\text { of all ages. Xerox Palo Alto Research } \\
\text { Center, } 1972 \text {. }\end{array}$ \\
\hline [13] & $\begin{array}{l}\text { Y. Karagiorgi, L. Symeou. Translating } \\
\text { Constructivism into Instructional Design: } \\
\text { Potential and Limitations. Educational } \\
\text { Technology \& Society, v.8, n.1, p. 17-27, } \\
2005 \text {. }\end{array}$ \\
\hline [14] & $\begin{array}{l}\text { L.S. Vygotsky [7 p.86] APUD J.A. Valente } \\
\text { [19 p.37]. }\end{array}$ \\
\hline [15] & $\begin{array}{l}\text { P. Freire. Educação e Mudança. 12.ed. São } \\
\text { Paulo, Paz e Terra, 1986, p. } 28\end{array}$ \\
\hline [16] & $\begin{array}{l}\text { M.S.P. Boehme. A contribuição da escola } \\
\text { no processo de tecnoletramento. Tese de } \\
\text { Mestrado, Universidade do Estado de Santa } \\
\text { Catarina, Abril de } 2003 \text {. }\end{array}$ \\
\hline [17] & $\begin{array}{l}\text { P. Freire. A Educação na Cidade. } 2 \text { ed. São } \\
\text { Paulo, Cortez APUD M.E.B. Almeida. } \\
\text { Informática e Educação: diretrizes para } \\
\text { uma formação reflexiva de professores. } \\
\text { Tese de Mestrado. Pontifícia Universidade } \\
\text { Católica de São Paulo. 1996, p. } 33 \text {. }\end{array}$ \\
\hline [18] & $\begin{array}{l}\text { S.A. Papert. A máquina das crianças: } \\
\text { repensando a escola na era da informática. } \\
\text { Porto Alegre, Artes Médicas, } 1994 .\end{array}$ \\
\hline [19] & $\begin{array}{l}\text { J.A. Valente. Por quê o computador na } \\
\text { educação?. Computadores e conhecimento } \\
\text { - Repensando a educação. Campinas,SP, }\end{array}$ \\
\hline
\end{tabular}

\begin{tabular}{|c|c|}
\hline & $\begin{array}{l}\text { Gráfica Central da UNICAMP, 1993, cap. } \\
2 .\end{array}$ \\
\hline [20] & $\begin{array}{l}\text { P. Mayo. Critial literacy and emancipatory } \\
\text { politics: the work of Paulo Freire. Int. J. } \\
\text { Educational Development. v.15, n.4, p. } \\
\text { 363-379, } 1995 \text {. }\end{array}$ \\
\hline [21] & $\begin{array}{l}\text { Wikipedia. Filosofia da Ciência. } \\
\text { http://pt.wikipedia.org/wiki/Filosofia_da_ci } \\
\text { \%C3\%AAncia, acesso em } 07 \text { set. } 2009\end{array}$ \\
\hline [22] & $\begin{array}{l}\text { E. Morin. Introduction à la pensée } \\
\text { complexe. Éditions du Seuil, 2005, p. } 13\end{array}$ \\
\hline [23] & $\begin{array}{l}\text { R. J. J. Arendt. Construtivismo ou } \\
\text { construcionismo? Contribuições deste } \\
\text { debate para a Psicologia Social. Estudos de } \\
\text { Psicologia. v.8, n.1, p.5-13, } 2003\end{array}$ \\
\hline [24] & $\begin{array}{l}\text { K. Liu. Semiotics in Information Systems } \\
\text { Engineering. MIT Press, } 2000 .\end{array}$ \\
\hline [25] & $\begin{array}{l}\text { D. Squires, A. McDougall. Choosing and } \\
\text { using educational software: a teachers' } \\
\text { guide. London, Routledge, 1994, cap. } 6 \text {. }\end{array}$ \\
\hline [26] & $\begin{array}{l}\text { S. Bertoldi. Avaliação de software } \\
\text { educacional - Impressões e Reflexões. } \\
\text { Dissertação de Bacharelado, Universidade } \\
\text { Federal de Santa Catarina, } 1999 .\end{array}$ \\
\hline [27] & $\begin{array}{l}\text { J.A. Valente. Análise dos diferentes tipos } \\
\text { de software usados na educação. O } \\
\text { computador na sociedade do conhecimento. } \\
\text { Campinas, SP, UNICAMP/NIED, 1999, } \\
\text { cap. } 4 .\end{array}$ \\
\hline [28] & $\begin{array}{l}\text { M.C.C. Baranauskas et al. Uma Taxonomia } \\
\text { para ambientes de aprendizado baseados no } \\
\text { computador. O computador na sociedade } \\
\text { do conhecimento. Campinas, SP, } \\
\text { UNICAMP/NIED, } 1999 \text {, cap. } 3 \text {. }\end{array}$ \\
\hline [29] & $\begin{array}{l}\text { M. Gadotti. Perspectivas atuais da } \\
\text { educação. São Paulo em } \\
\text { Perspectiva. v.14, n. } 2,2000 .\end{array}$ \\
\hline [30] & $\begin{array}{l}\text { J.A.Valente. Informática na educação no } \\
\text { Brasil: análise e contextualização histórica. } \\
\text { O computador na sociedade do } \\
\text { conhecimento. Campinas, SP: } \\
\text { UNICAMP/NIED, } 1999 \text {, cap. } 1 .\end{array}$ \\
\hline [31] & $\begin{array}{l}\text { Free Software Foundation, GNU General } \\
\text { Public License v2.0, } \\
\text { http://www.gnu.org/licenses/old- } \\
\text { licenses/gpl-2.0.txt, acesso em: } 09 \text { mar. } \\
2008 .\end{array}$ \\
\hline
\end{tabular}

